\title{
KÁLMÁN BARSY, UN ESCRITOR HÚNGARO EN PUERTO RICO
}

\author{
LABONCZ ZSUZSA
}

Universidad de Szeged

\begin{abstract}
The name of this Hungarian-born, Latin American writer may sound unfamiliar to us, Hungarian readers, but nowadays Kálmán Barsy is one of the most popular and bighly recognized authors in America, whose very first novel was honored with the prize Casa de las Americas in 1982. His novels, sbort stories and essays have been published in several languages, but we can only read one of them in Hungarian. No doubt, this work occupies a very important place in our literature, as it is treating a less known subject, the story of the socalled second generation of the emigration. This second generation bas only a few members like Kálmán Barsy, who shares bis homeland memories, and the difficulties of the integration into a new and strange community. With this study I try to present not just bis life and work, but also the way be describes the experience of an emigrant of the second generation.
\end{abstract}

\section{Prólogo}

En las últimas décadas, sobre todo después del cambio de régimen político en 1989-1990, podemos observar un incremento enorme de las investigaciones sobre la emigración húngara en América Latina, gracias a que el Archivo Nacional y las bibliotecas divulgaron numerosos documentos respecto al tema. En 1999 la Academia Húngara en colaboración con el Departamento de Estudios Hispánicos de la Universidad de Szeged incluso fundó un grupo de investigación para estudiar la emigración latinoamericana, y en los últimos años cada vez más estudiantes de grado y de postgrado del departamento eligen este tema para su tesis, o para tema de investigación. ${ }^{1}$

Junto a las relaciones históricas y a la emigración, varios estudios salieron a luz dentro del tema de las relaciones literarias hispano-húngaras también. Uno de los más extensos es el trabajo del historiador de literatura Salvador Bueno, publicado en $1977^{2}$, y el de László Scholz de $2005^{3}$, que contiene una bibliografía detallada sobre las traducciones húngaras entre 1950 y 2004. Tenemos que mencionar también el libro de Judit Némethy Kesserü que se ocupa de la

1 Péter TORBÁGYI, Magyarok Latin-Amerikäban, Budapest, Magyar Nyelv és Kultúra Nemzetközi Társasága, 2004., 9-26.

2 Salvador BUENO, Cinco siglos de relaciones entre Hungria y América Latina, Budapest, Corvina, 1977.

${ }^{3}$ László SCHOLZ, A spanyol-amerikai irodalom rövid története, Budapest, Gondolat, 2005. 
historia de la emigración húngara en Argentina y ofrece una amplia bibliografia sobre la literatura húngara en este país. ${ }^{4}$

Una rama muy interesante de las investigaciones sobre las relaciones literarias hispano-húngaras es el estudio de la actividad de los poetas, novelistas emigrantes, como la de Zsigmond Remenyik, György Ferdinandy, Márton Kerecsendi Kiss o Susana Wein. Con este trabajo quisiera continuar estas investigaciones.

Kálmán Barsy es un escritor latinoamericano, de origen húngaro, perteneciente a la segunda generación de los emigrantes. Se crió en Argentina, pero actualmente vive y trabaja en Puerto Rico. En el mundo hispano es muy conocido y reconocido, galardonado con numerosos premios literarios. Sin embargo, en su país natal sólo a pocos les suena su nombre, puesto que todavía solamente un libro suyo 5 se ha publicado en Hungría con la ayuda de su amigo György (Georges) Ferdinandy, que vivió también en Puerto Rico durante varios años. Este libro recibió muy buenas críticas, sin embargo no se ha oído nada de él desde entonces, y desgraciadamente tampoco se tradujeron al húngaro otras obras suyas. Aparte de una memoria de licenciatura ${ }^{6}$ todavía no se ha escrito un trabajo en húngaro que integre su vida y obra entera hasta este momento. Por tanto, para la elaboración de mi trabajo mis fuentes básicas han sido sus obras, principalmente dos, la ya mencionada la cabeza de mi padre, publicada en húngaro también, y Los veinticuatro dias ${ }^{8}$, además, los diferentes artículos, críticas y entrevistas tanto de la prensa hispanoamericana como de la húngara. Fuera de esto, me he puesto en contacto con el autor también, que muy amablemente ha respondido a mis preguntas, y gracias a esta entrevista he recibido una imagen detallada sobre su vida.

El objetivo de mi trabajo -además de presentar la vida y la obra literaria de este autor- es estudiar con la ayuda de dos obras suyas cómo aparece en su novelística la problemática de la identidad y la de la patria-apátrida, junto con los recuerdos de las raíces húngaras y las dificultades de adaptarse a la nueva patria, $y$ al final el regreso a la tierra natal.

\footnotetext{
${ }^{4}$ Judit NÉMETHY KESSERŨ, "S qabadságom lett a börtönöm". Aq argentinai magyar emigráció története 1948-1968, Budapest, 2003.

${ }^{5}$ Kálmán BARSY, Apám arcvonásai, Budapest, Orpheusz Könyvek, 2000.

' Katalin KOVÁCS-KORBEL, Vida y obra literaria de Kálmán Barsy, Szeged, 2008.

${ }^{7}$ Kálmán BARSY, La cabeza de mi padre, Valencia, Editorial Pre-Textos, 2002.

${ }^{8}$ Kálmán BARSY, Los veinticuatro dias, Valencia, Editorial Pre-Textos, 2009.
} 


\section{La biografia en breve}

Kálmán Barsy nació en Budapest, en el año 1942. Al final de la Segunda Guerra Mundial, cuando las tropas soviéticas ocuparon el país, su familia se trasladó a Austria y algunos años más tarde continuaron su ruta hacia América Latina, en busca de una nueva patria. Llegaron a Argentina en 1949 a bordo de un buque de guerra estadounidense, el General Langfitte, que -como parte del Plan Marshall- transportaba a los emigrantes europeos.

El primer año en Argentina fue muy difícil para la familia entera: no hablaban español, sólo su lengua materna y alemán. Su padre, que era ingeniero, no consiguió encontrar trabajo, y su madre se vio obligada a trabajar de sirvienta. Debido a estas circunstancias los niños, Kálmán y su hermano mayor, vivieron en el orfanato de la colonia alemana durante ese año. Por las mañanas estudiaban en el colegio público argentino, en español, y por las tardes tenían clases en alemán. El escritor recuerda esa época como una experiencia bastante triste y traumática, ya que por primera vez en su vida tuvo que separarse de sus padres.

Cuando el año siguiente su padre consiguió un empleo en el municipio, se establecieron en Ituzaingo, a 25 kilómetros de la capital argentina.

Ya de pequeño le interesaba la literatura. Con la ayuda de cómics aprendió el español, más tarde empezó a leer libros de aventuras. A los doce leyó Crimen y castigo, pero sólo los diálogos, dejando las partes aburridas. En casa no tenían muchos libros, pero una de sus maestras -al ver su gran afán de leer- le prestaba sus propios libros.

A los 21 años recorrió el continente americano con un amigo suyo, haciendo autoestop. En las ciudades a las que llegaban decían que eran estudiantes de sociología, y que viajaban para recoger materiales para un libro. La prensa local les hacía entrevistas, y cuando llegaron a otro lugar, mostrando al alcalde estos artículos, recibían alojamiento y comida gratis. Es una coincidencia muy interesante que más tarde, leyendo el libro de apuntes del joven Che Guevara, y viendo la película Diarios de motocicleta, se diera cuenta de que él y su amigo recorrian los mismos lugares que Che, sólo que diez años más tarde. Pero Barsy, por una beca estadounidense interrumpió este viaje.

Después de terminar sus estudios en la Universidad se trasladó a Europa, primero a Francia, luego a España. A finales de la década de 1960 regresó a Argentina donde trabajó como socorrista, y también dio clases de inglés y francés. 
Como quería continuar sus estudios, volvió a los Estados Unidos, a Nueva York. Trabajaba de mozo en un restaurante húngaro, mientras hacía la maestría en la Columbia y más tarde el doctorado en la Universidad de Nueva York.

Desde 1974 vive en Puerto Rico, y enseña literatura en la Universidad.'

\section{Sus relaciones con Hungria}

Las relaciones del escritor con su país natal eran siempre a través de sus padres y de los demás emigrantes de la colonia húngara argentina. En la región donde vivían, sólo había dos húngaros más, por tanto, no podemos hablar de una colonia tan organizada como en aquella parte de Argentina donde habitaba la mayoría de los emigrantes húngaros.

Su familia no participaba activamente en la vida colonial, él fue sólo una vez a un campamento de verano con los boy-scouts. En cuanto a la lengua materna, en casa hablaba en húngaro con sus padres, pero con su hermano en castellano. Su madre les enseñaba a lèer y escribir en húngaro. Incluso cuando ya era adulto, ella corregía las cartas que su hijo le enviaba de sus viajes, y se las devolvía para que aprendiera. A pesar de esto, el escritor dice que no sabe escribir correctamente en su lengua materna, sin embargo habla muy bien el húngaro coloquial, mucho mejor que la mayoría de los emigrantes de su generación, que se debe a su facilidad para las lenguas. La familia no tenía contacto con los parientes que quedaron en Hungría, sólo su madre mantenía correspondencia con su hermano, Guszti, que a menudo les enviaba revistas deportivas húngaras. Pero su padre nunca escribió a su hermana. Tampoco pensaban en el regreso, al principio porque era imposible, y más tarde sus padres ya se sentian muy viejos para el viaje. Su hermano, tres años mayor que él, se asimiló totalmente a la Argentina, y nunca se interesó por su pais natal. Sin embargo Kálmán ya a los 23 años hizo un viaje a Hungría, y más tarde también regresó, esta vez a propósito de la publicación de su novela, titulada La cabeza de mi padre, en húngaro. ${ }^{10}$

\footnotetext{
${ }^{9}$ Entrevista (8 de octubre de 2010.), HERNÁNDEZ Carmen Dolores, "Kalman Barsy: los diarios del auto-stop", Renista Foro, 12 de junio de 2005.

${ }^{10}$ Entrevista (8 de octubre de 2010.)
} 


\section{De aventurero a escritor}

A pesar de su afán por la literatura y la lectura, empezó a escribir bastante tarde, por su preocupación de no tener éxito inmediato."

Su primer cuento, titulado Las trenzas coloradas, se publicó en la revista $\operatorname{Sin}$ Nombre ${ }^{2}$. Después, escribió su primer cuento para niños, bajo el título $D e l$ nacimiento de la isla de Borikén, y otros maravillosos sucesos, que fue galardonado en 1982 con el Premio de la Casa de las Américas. Este libro, que se publicó en Cuba también, trata de la historia de Puerto Rico, en forma mitológica ${ }^{13}$.

Desde entonces el número de sus publicaciones sigue en aumento continuo, en las casi tres décadas pasadas publicó numerosos relatos, novelas y cuentos infantiles.

En sus escritos predominan los elementos autobiográficos. En el Naufragio por ejemplo dos personajes evocan la figura del autor: Péter Kocsis, de origen húngaro, que enseña literatura comparativa en una universidad estadounidense, y su amigo Frank Erkens, un actor, que igual que el autor, llegó de Europa a América en su niñez, a bordo del General Langfitte ${ }^{14}$, y su novela Verano evoca aquél periodo de su vida, cuando al regresar a Argentina tras una estancia en Europa, empezó a trabajar como socorrista.

Sin embargo, llama nuestra atención que en sus escritos la figura del autor no es idéntica a la del narrador ${ }^{15}$, en sus obras utiliza los elementos de la realidad como ficción.

Otro elemento importante de su narrativa es el humor y la ironía -distinguido por los críticos como un humor típico centroeuropeo- y la erótica, que según el autor mismo no es el tema verdadero, sino aparece en el fondo, pero de todas maneras está presente en sus obras. ${ }^{16}$ Por ejemplo en Amor portátil dos jóvenes Tulio y Alonso- emprenden el negocio de su vida: recorrer América Latina con un burdel ambulante, en el que munecas hinchables sustituyen a las verdaderas prostitutas. Obviamente el tema real aquí no es este, sino la situación actual de

\footnotetext{
${ }_{11}$ Miguel MORA, “Reportaje: La extraña historia de Kalman Barsy”, El Pais, 28 de enero de 2003.

12 Esta revista fue publicada por primera vez en 1970, por la Editorial Sin Nombre, y en la actualidad todavia sigue existiendo. "Sin Nombre", latindex: Sistema Regional de Información en Linea para Renistas Cientificas de Anérica Latina, el Caribe, España y Portugal, asequible en: http://wrww.latindex.unam.mx/ buscador/ficRev.html?folio=4186\&opcion=1, fecha de consulta: 25 de octubre de 2010 .

13 Zsuzsa DÁRDAI, "Ember vagyok, aki ir', Magyar Narancs, 8 de abril de 1993., 37.

${ }^{14}$ Kálmán BARSY, Naufragio, Editorial E.D.H.A.S.A., Barcelona, 1998.

${ }^{15}$ Héctor APONTE ALEQUÍN, "Perdona y escribe", Primera hora, asequible en: htт://www.primerahora.com/perdonayescribe-335171.html, fecha de consulta: 23 de abril de 2011. 16 Zsuzsa DARDAI, op. cit.
} 
América Latina de aquél entonces, con la que se enfrentan los jóvenes durante su viaje: el caciquismo, la mafia, el militarismo, la religión etc. ${ }^{17}$

\section{La cabeza de mi padre}

La cabeza de mi padre ocupa un lugar especial en la obra del escritor, puesto que es su libro más personal. En una entrevista lo explica así:

'Este libro es especial para mi porque, más allá de su escritura, me ba permitido reflotar cosas tan profundas como mi relación con el idioma húngaro, un vinculo mágico, ya que no tengo un conocimiento gramatical de esa lengua, pero conservo palabras profundamente familiares, que me tocan emotivamente" 18

Además, es la única novela suya que se ha publicado en su lengua materna también, hasta ahora, lo que significa que sólo a través de este libro le puede conocer el público húngaro. Pero a pesar de esto, György Ferdinandy Łel traductor de la novela- la considera como una de las obras más significativas de la literatura húngara, puesto que trata un tema poco conocido de la emigración húngara: la historia de la segunda generación.

Ferdinandy tiene un papel importante en el nacimiento de esta obra: hace unos años enfermó y Barsy le regaló un cuento suyo sobre un viejo que quería recuperar los sabores de su juventud. La historia fascinó al enfermo de tal manera, que pidió a su amigo que escribiera más relatos parecidos para que los tradujera al húngaro y que los publicaran después. Barsy al principio quería escribir una novela más larga, pero al final decidió no modificar estos breves núcleos narrativos, porque pensaba que así, con los vacios y silencios tenían más fuerza. La edición española lleva el subtítulo Novela corta en trece módulos, que se pueden leer incluso independientemente, en cualquier orden. ${ }^{19}$ Sin embargo el género al que pertenece -aunque aparece en el subútulo- no es muy evidente, ni siquiera su traductor está seguro en cuál se podría incluir. ${ }^{20}$

17 "Amor portátil", IberLibr.com: Pasion por los libros, asequible en: http://www.iberlibro.com/ servlet/BookDetailsPL?bi=3333522750\&searchurl=kn\%3Damor\%2Bport $\% 25 \mathrm{E} 1 \mathrm{ril} \% 26 \mathrm{vcat} \% 3 \mathrm{D}$ Argentina_ficci_n n\%26vcatn\%3DArgentina\%2Bficci\%25F3n\%26vci\%3D52644675, fecha de consulta: 10 de octubre de 2010.

18 Emma RODRIGUEZ, "Kalman Barsy reflexiona sobre el exilio y la pertenencia", Telemundo, asequible en: http://foros.msnlatino.telemundo.com/Telemundo/lofiversion/index.php/t12865.huml, fecha de consulta: 24 de octubre de 2010.

${ }^{19}$ Audioconferencia

${ }^{20}$ György FERDINANDY, “A pénz természete”, Magyar Napló - septiembre de 2003, asequible en: http://www.magyarnaplo.hu/read.php?id=67, fecha de consulta: 10 de septiembre de 2010 . 
La cabeza de mi padre se refiere a aquella máscara de yeso que representa el rostro del joven Zoltán Benedek, padre del protagonista de la novela. Pero esta máscara existe también en la realidad, hecha también sobre el rostro del padre de Barsy por un compañero suyo hace muchas décadas. Cuando el escritor regresó a Hungria, a los 23 años, visitó a algunos de sus parientes y entonces recogió la máscara de su padre entre fotos y otros recuerdos familiares. ${ }^{21}$

El libro fue publicado primero en húngaro, por la Editorial Orpheusz, y sólo dos años más tarde en español. Además fue traducido también al inglés y al francés. Las palabras que en el texto húngaro aparecen en cursiva, en las demás versiones también se figuran en cursiva y en húngaro.

\section{Detrás de las palabras}

La cabeza de mi padre es una especie de saga familiar sobre los Benedek, emigrantes húngaros en la Argentina. Sin embargo, la emigración sólo aparece en la historia como circunstancia, y el verdadero tema es la problemática de la pertenencia, la de la identidad, cómo es posible adaptarse a la nueva vida para las diferentes generaciones de la familia etc. ${ }^{22} \mathrm{La}$ edición española comienza con un prólogo precioso, lírico, cuyas líneas reflejan perfectamente el ambiente de la novela:

'La emigración y el exilio son el naufragio del alma, un catastrófico bundimiento al que sólo una parte del ser sobrevive. El náufrago pasa su existencia recorriendo la playa, tratando de armar el rompecabezas de su vida a partir de los tesoros y basura que le trae la resaca. Es un ser por siempre disperso, becho de los escombros que trajo el mar. Objetos, palabras, sabores perdidos, fragmentos de viejas historias, son su herencia. Y el ovillo del tiempo soltando el bilo como el canto de un pajaro en el aire." 23

Con estas frases se pone bastante claro y comprensible por qué funcionan tan bien estos pequeños núcleos narrativos, y por qué no extrañamos una historia más larga y coherente; los trozos de las historias, los fragmentos de los recuerdos son los mosáicos de la vida de un emigrante.

En el centro de la historia se encuentran dos hermanos, Atrila y Laci, que aparecen como una especie de Caín y Abel moderno, como la doble personalidad del autor, que representan dos extremos de la búsqueda de identidad. Attila, el más joven quiere saber quién es, de dónde proceden sus raíces, mientras que Laci, el mayor, sólo utiliza las fotografías familiares como postales. La vida del primero es inmutable, con un destino abierto, y la del

\footnotetext{
${ }^{21}$ Entrevista (8 de octubre de 2010.), Audioconferencia

22 Emma RODRIGUEZ, op. cit.

${ }^{23}$ Kálmán BARSY, La cabeqa de mi padre, Valencia, Editorial Pre-Textos, 2002., 11.
} 
segundo es movida, aventurera, y su destino queda concluido. ${ }^{24}$ Laci es el que narra la historia, pero desde el punto de vista de su hermano, a veces en primera, otras veces en tercera persona del singular.

Para el final de la novela las dos figuras se confunden, se produce una fusión, una síntesis de los personajes. Según el autor, el último paso en la búsqueda de nuestra identidad, es la síntesis de las partes que nos constituyen. Eso aparece cuando Laci y Attila se funden en uno. Durante esa sintesis el viajero, el aventurero muere, pero al mismo tiempo se convierte en su propio hermano, que es prácticamente su contrafigura: un marido, un padre de familia que vive una vida simple y rutinaria. $Y$ así, el círculo se cierra. ${ }^{25}$

Es un dato curioso, que el hermano de Barsy tiene otro nombre, que es Attila, y sigue viviendo en Argentina ${ }^{26}$, por tanto podemos identificarlo con la figura de Attila de la novela, que permanece también en el lugar donde pasó su vida entera, y desde allí contempla y admira las aventuras de su hermano.

La base de la historia es la autobiografía del autor, cuya persona es perceprible tanto en la figura de Laci, como en la de Atrila. Y en cada relato se puede descubrir algún momento de la vida de Barsy. La familia húngara que emigra a Argentina después de pasar algunos años en Austria, obviamente evoca la familia del autor. El orfanato "Marie Luise Helm" que aparece en el capitulo titulado Verbo divino, hace recordar al orfelinato de la colonia alemana donde el autor y su hermano tuvieron que pasar un año entero después de llegar a Argentina. Traduttore, tradittore evoca los años cuando Barsy fue el intérprete de sus padres, quienes a pesar de poder comunicar más o menos con la gente, no llegaron a aprender bien el español. A diferencia de lo que aparece en el libro, en realidad no encontraron personalmente con Eva Perón, sólo mandaron una carta a la Fundación Eva Perón pidiendo ayuda para que su padre encontrara por fin un empleo. Los capitulos Los viajes de Laci y Gulliver se basan en los viajes del autor, y el Álbum de familia rememora aquel periodo de su vida, cuando vivió en los EEUU con varios amigos en la casa de una anciana, cuyas fotos fueron utilizadas como postales por los jóvenes. ${ }^{27}$

${ }^{24}$ Zsófia SZILȦGYI, “Egy idegen a Lánchídon”, Tiszataj, 2001/7, 102.

${ }^{25}$ Audioconferencia

${ }^{26}$ Audioconferencia

27 Audioconferencia 


\section{La cuestión de la identidad}

En el fondo de cada frase de la historia está presente la pregunta: ¿quién soy' yo?, ¿de dónde vengo? Attila se siente extraño, ni en el mundo, ni en su propia familia encuentra su sitio. Además le duele que su hermano, Laci, sea capaz de adaptarse muy pronto a cualquier lugar, a cualquier situación, además, su padre también aprecia más a su hijo mayor. Por tanto Attila teme que en realidad él no pertenezca a ninguna parte: se busca en vano en las fotos, no descubre ni un rasgo que le parezca familiar:

'Poco a poco, a partir de la enloquecida dispersión del bermano viajero, va tomando forma el álbum familiar. Es un vasto rompecabezas con infinitas piezas sueltas, pero en ninguna de ellas está Attila. Él no está." 28

Plantea la pregunta a su madre también, pero ella -que entonces ya padece del Alzheimer, e incluso confunde a sus dos hijos- no contesta:

"QQuién soy madre? ¿De dónde vengo? ... Déjame ya, Laci - me implora, confundiéndome con mi bermano." 29

Las figuras de los hermanos al final de la historia se funden completamente, y no sólo en la mente de su madre enferma. Las contrafiguras se sintetizan en una sola persona.

En cuanto a la cuestión de la identidad, merece la pena mencionar el capítulo que se titula El tesoro Benedek, en el que el pequeño Attila quiere demostrar al pueblo entero que ellos son húngaros y no gitanos; aunque él mismo tampoco sabe exactamente cuál es la diferencia entre los dos, le da rabia que los argentinos los confundan. Hasta la maestra. $\mathrm{Ni}$ a sus padres, ni a Laci le molesta esto, sin embargo él sufre de que lo tomen por gitano, por tanto decide mostrar a su maestra aquella moneda de plata que lleva el retrato de San Esteban, y que en casa, entre ellos, en broma la llaman el tesoro Benedek. Así piensa demostrarle su origen:

"Con su inocente lógica de niño y sin baber jamás leido a Brecbt, Attila razonó que la señorita Tinto, a partir de esa moneda, babría de inferir la existencia de un sistema monetario, de un Estado y de una bistoria nacional, incompatibles con las nómadas tribus de gitanos que vendian chatarra en la Argentina." 30

Sin embargo la maestra cree que es un regalo para ella, ya que los gitanos tienen tantas monedas... Y el intento de Attila fracasa.

\footnotetext{
${ }^{28}$ Kálmán BARSY, op. cit., 84.

${ }^{29}$ Ibidem, 103.

${ }^{30}$ Ibidem, 45.
} 
A través de los ejemplos anteriormente mencionados, también se ve claramente la diferencia entre los hermanos: Attila, ya en su niñez quiere saber quién es, y que de dónde viene, y hacerlo explícito también para los demás. Pero en realidad, nunca consigue encontrar la respuesta. Laci, en cambio, parece que está totalmente seguro en su identidad, o tal vez con sus continuos viajes, andanzas e inquietudes intente enmascarar esta misma inseguridad.

\section{La continuación de la saga familiar}

Hace dos años salió a luz Los veinticuatro dias, que se considera como la continuación de La cabeza de mi padre. Recibió muy buenas críticas, y además obtuvo el premio de Novela Corta José María de Pereda ${ }^{3 i}$. En este libro el protagonista László Benedek -Laci de la novela anterior-se ve obligado a dejar su hogar, tras ser falsamente acusado de violencia doméstica por su esposa. La policía le deja veinte minutos para recoger todo lo necesario y dejar la casa. Entre las pocas cosas que empaqueta, László decide llevar consigo la máscara de su padre, con el fin de regresar a su tierra natal y enterrar alli simbólicamente a su padre, o sea, la máscara de yeso que representa su figura. Su viaje es al mismo tiempo un viaje interior, puesto que durante esos veinticuatro días revaloriza toda su vida, sus matrimonios fracasados, el amor y la vejez.

En esta novela se aclaran varios episodios de la vida de los Benedek, y encontramos la respuesta para algunas preguntas que en La cabeza de mi padre han quedado abiertas. Sin embargo, hallamos también una serie de acontecimientos ya conocidos, por tanto los que no han leído la otra novela, también se enteran de la historia de la familia Benedek a través de los recuerdos de Laci.

La historia se presenta en tres planos temporales: los veinticuatro días, que aparecen ya en el título, se refieren al presente; desde el día de la partida, hasta que el protagonista arroja la máscara de yeso al río Maros. Estos acontecimientos, o sea los que tienen lugar en el presente, predominan en la novela, $y$ siguen el orden cronológico, puesto que el libro se ha escrito en forma de un diario de viaje, por tanto el título de los capítulos también se refiere a esta cronología: DÍA 1, DÍA 2, DÍA 3 etc.

El segundo plano temporal es el del pasado, cuyos acontecimientos aparecen ocasionalmente durante el viaje del protagonista, se relacionan a lo sucedido en el presente, pero no siguen el orden cronológico. Son los recuerdos de la infancia, de sus viajes anteriores, de los momentos felices iniciales de sus

31 Este premio lleva el nombre del escritor cantábrico, José Maria de Pereda, y lo conceden anualmente a autores de novelas inéditas, escritas en castellano, que no han obtenido todavía este premio, y que responden a las condiciones de participación. "Premios", El digoras, asequible en: http://www.eldigoras.com/premios/premios0574hthml, fecha de consulta: 28 de noviembre de 2010. 
matrimonios y también de los no tan felices, incluso devoradores de los meses finales de dichas relaciones. Además, aparecen también recuerdos del pasado colecrivo, de la Segunda Guerra Mundial, del Holocausto y de los horrores de la dictadura comunista también. Los espiritus de sus parientes y de sus amigos de Ituzaingó también acompañan a Laci a lo largo de su viaje: por ejemplo descubre la figura de su madre en varias mujeres en Budapest, y su padre está con él físicamente también, puesto que está viajando con su máscara.

El último plano temporal equivale al mundo del subconsciente, al de los sueños, que poseen un significado importante y simbólico en la obra. Merece la pena mencionar por ejemplo el de la Ciudad Feliz, que aparece dos veces a lo largo de la historia. Primero en el primer capítulo, en el que el protagonista nos explica su significado también, según el cual el regreso a la Ciudad Feliz se refiere al regreso al útero. Más tarde este mismo sueño, mejor dicho el recuerdo de este sueño, aparece otra vez ya casi al final de la historia, cuando el protagonista, paseando por el cementerio Farkasréti, siente haber encontrado este lugar, o sea la Ciudad Feliz, que hace muy poco todavía le parecía inalcanzable, puesto que tras tener que abandonar su casa, y para colmo le quitaron su único equipaje en el acropuerto, sentía que había perdido todo, no le quedaba nada, ya no pertenecía a ningún lugar: "Loveless, bomeless, wifeless." " $32 \mathrm{Le}$ apresaba aquella misma sensación de pérdida que sentia en su niñez cuando tenían que ir huyendo del pais, y por tanta prisa se le cayó uno de sus zapatos. Este recuerdo nunca le dejó tranquilo. Sin embargo este viaje, el regreso a su tierra natal le ayuda encontrar de nuevo el lugar que había perdido antes, que no tiene que ser precisamente un lugar geográfico concreto, más bien es un sitio donde se siente feliz, tranquilo y seguro.

A lo largo del viaje se aclaran para el protagonista algunos acontecimientos muy importantes del pasado de su familia, que cambian toda su vida: se entera de por qué tuvieron que dejar el país, y por qué se fueron a Argentina. Se pone de manifiesto también por qué su padre no se puso en contacto con la colonia húngara y por qué se distanció de él su hermano. La verdad se descubrió por casualidad, en una sola frase suelta:

"Lo mejor que bizo su padre fue emigrar. Aqui no bubiese podido escapar a la venganza judia." 33

Más tarde nos enteramos también de los detalles, cuando László lo pregunta directamente a uno de sus familiares:

"A tu padre lo acusaban de participar en la organización de las brigadas de trabajos forzados de los judios de Budapest. (...) Eran tiempos duros. Alguien no aguantó el trabajo o murió de

${ }^{32}$ Kálmán BARSY, Los neinticuatro dias, Valencia, Editorial Pre-Textos, 2009, 20-28.

${ }^{33}$ Ibidem, 193. 
frío y ya eras responsable. Dos o tres judios daban testimonio. Listo. Criminal de guerra. Así nomás, jun bombre como tu padre!" "3

Este descubrimiento derrumbó totalmente aquella imagen que el protagonista guardaba sobre su padre en sus recuerdos: un hombre que está trabajando heróicamente con los registros de catastro y topografía en su oficina, mientras bombardeaban la ciudad, que por tener una inteligencia excepcional, probablemente tenia varios enemigos, por tanto lo mejor que podía hacer fue emigrar. ${ }^{35}$ Entonces comprende por qué tenía su padre una pistola en casa, por qué eligió Argentina como destino final y por qué se empeoró su relación con su otro hijo. Parece que todos lo sabían, menos László. Pero aún le parece incomprensible que después de todo eso el mejor amigo de su padre en la emigración era un judio, Emil Stern.

Este tema aparece ya al inicio de la historia, pronosticando así lo que va a pasar: en esta parte László habla con algunas personas recién conocidas sobre dos novelas famosas de Péter Esterházy - Harmonia Caelestis y Javitott kiadás (Edición corregida). En la primera Esterházy exalta la figura de su padre, Mátyás Esterházy, y en la segunda derrumba esta imagen tras descubrir que su padre fue informante de la AVO (Autoridad de Protección de Estado). ${ }^{36}$

El protagonista, a pesar de saber ya la verdad sobre el pasado de su padre, no renuncia a su plan original de llevar la máscara de su padre a su pueblo natal, y enterrarla alli. Sólo lo modifica un poco, y en vez de enterrarla, la arroja al río: "¿Qué más se puede pedir, que lo devuelvan a uno al rio de su infancia?" 37

Parece que al tirar la máscara al Maros, se encuentra a sí mismo, y ya sabe la respuesta de aquella pregunta que en La cabeza de mi padre quedó sin contestar:

"-Tú eres el bijo de Zoltán - dijo entonces Omama Gizella, reconociéndome al fin. -Ahora si- respondi." 38

En aquella novela se menciona la sospecha de que a lo mejor el padre de uno de los hermanos no es Zoltán. Tal vez con esta última frase el protagonista acabe con este pensamiento que le hacía sufrir durante muchos años, y parece que asi perdona el pasado de su padre, aunque ya nunca será capaz de verlo tal como antes. Por eso se puede considerar esta obra como la novela del perdón y de la reconciliación. ${ }^{39}$

\footnotetext{
34 Ibidem, 229.

35 Ibidem, 72.

${ }^{36}$ Ibidem, 122-125.

${ }^{37}$ Ibidem, 264.

${ }^{38} \mathrm{Idem}$.

39 "Kalman Barsy - Los veinticuatro dias", Telemundo, asequible en: hrtp://foros.msnlatino.telemundo. com/Telemundo/lofiversion/index.php/t12865.html, fecha de consulta: 24 de octubre de 2010 .
} 


\section{Motivos característicos}

En la novela aparecen los mismos elementos autobiográficos que en La cabeza de mi padre, pero se complementan con más detalles como la actividad del padre durante la Segunda Guerra Mundial, la razón de su emigración etc. Son muy interesantes las referencias a la novela anterior, ya que el protagonista se presenta como autor de tal libro.

Incluso aparece el traductor, György Ferdinandy, como M., a quien conoció en Puerto Rico, y nos enteramos también de las circunstancias del nacimiento de esta obra:

"Todo habia comenzado con la enfermedad de M. Yo estaba escribiendo una larga novela, tipo saga familiar, cuando lo operaron y fui a visitarlo al bospital. (...) La gente les lleva flores o golosinas a los enfermos; yo también quise llevarle algo. Se me ocurrió entonces reescribir, imitando el parco estilo del propio $M$., un pequeño episodio de mi novela y llevárselo a modo de degustación. (...) A partir de ese momento no tuve paz; el apetito traductor de M. era insaciable. (...) En pocos meses tuvimos un libro. Mi novela corta se publicó en traducción al buingaro antes que el original en castellano y se parecia muy poco a lo que estaba escribiendo anteriormente. Se parecia, en cambio, al estilo seco, de carne pegada al hueso, de los relatos de $M . "+0$

Las últimas frases parecen justificar la teoria de Zsófia Szilágyi, según la cual Ferdinandy, a través de la traducción, aparece en La cabeza de mi padre como una especie de padre literario. ${ }^{41}$

Tampoco falta el humor, elemento muy típico de la narrativa de Barsy. Pensemos por ejemplo en la figura del pariente Aladár, que sufre de narcolepsia, o en la historia de los inicios de su amistad con M.:

"Cuando conoci a M. en Puerto Rico, bace mucbos años, ambos desconfiábamos el uno del otro, tal vez por parecernos. Esta mutua desconfianza nos unió. Él pensaba que yo me acostaba con su esposa francesa y yo, que él era un agente de la $C L A$, un besúgó. jAh, los dulces años de la juventud cuando todo era tan simple! (...) Al final resultó que ni él era agente de la CIA ni yo me acostaba con su esposa francesa, pero ya era tarde. De tanto tratar de descifrarnos el uno al otro, terminamos siendo grandes amigos." +2

La relación del protagonista con las mujeres, la erótica, también tiene un papel importante en la historia. Según Carmen Dolores Hernández aparte de la búsqueda, éste es el motivo que domina en la novela, y aparece en formas muy diferentes. Dice que en esta historia las mujeres jalonan el camino del

\footnotetext{
${ }^{40}$ Kálmán BARSY, Los neinticuatro dias, 185-187.

${ }^{41}$ Ibidem, 181-187., y SZILÁGYT Zsófia, op. cit.

${ }^{42}$ Kálmán BARSY, op. cit., 176-177.
} 
protagonista. ${ }^{43}$ Su madre, que se ha sacrificado por su familia; sus dos esposas, de las que faltaba este tipo de beneficiencia, y ambas lo engañaron; Erzsi, Libuse etc. Además, los sueños de László son en gran parte de carácter erótico, influidos tal vez por su miedo de la imporencia, puesto que le han operado recientemente de cáncer de próstata.

\section{Conclusiones}

La literatura de Kálmán Barsy es un buen ejemplo para demostrar que merece la pena prestar atención a los escritores húngaros fuera del pais también. La cabeza de mi padre y Los veinticuatro días son unos libros destacables por ser obras de un autor, que a pesar de vivir casi su vida entera muy lejos del país donde nació, sigue ocupándose tanto de sus raices, de su identidad, que ha dedicado una parte importante de su literatura a este tema.

Su escritura siempre toma la realidad como base, que al entrar en el mundo de la ficción nos da un resultado particular, una nueva visión del mundo de la emigración y de los sentimientos de los exiliados, puesto que además se trata de un emigrante de la segunda generación, un tema bastante poco conocido en nuestra literatura.

Como vemos, Kálmán Barsy es un escritor polifacético, digno de atención, que ocupa un lugar importante en la literatura húngara contemporánea, por tanto como también lo dice György Ferdinandy- a pesar de escribir en español es, sin duda, un autor húngaro. ${ }^{+4}$ Considero muy importante que lo conozcan mejor en Hungría, y hacer asequible sus obras para los lectores húngaros también.

Sería interesante estudiar otras novelas y escritos suyos, ya que no sólo por estos dos libros que relatan el exilio y las raíces húngaras merece atención; el resto de su obra -la mayor parte-es también digno de atención, como ya he mencionado se trata de un escritor famoso y célebre, sobre todo en el mundo hispanohablante, pero actualmente -gracias a las traducciones al inglés y al francés- en cada vez mayor parte del mundo leen y reconocen su trabajo. ${ }^{45}$

${ }^{43}$ Carmen Dolores HERNÁNDEZ, "Volver - El retorno al pais natal de un emigrante es un viaje en el tiempo tanto como en el espacio", Telemundo, asequible en: http://foros.msnlatino.telemundo. com/Telemundo/lofiversion/index.php/t12865.html, fecha de consulta: 24 de octubre de 2010.

44 Kảlmán BARSY, Apám arcuonásai, 65-68.

${ }^{45} \mathrm{~A}$ continuación ofrecemos la bibliografia de Kálmán Barsy.

Libros publicados en español: Secretos de familia, novela juvenil, Colección El Barco de Vapor, núm. 3, serie roja, Puerto Rico, Ediciones SM, 2009; Pen Club Puerto Rico: Premio Nacional de literarura juvenil, 2009; Los veinticuatro dias, novela, Editorial Pre-Textos, Valencia, 2009; Premio de novela corta "José Maria de Pereda", 2008; La vagina de Platón, novela erótica, Editorial de la Universidad de Puerto Rico, Rio Piedras, 2007; Leyendas Insolitas: El Sacristan y su Verduga/Una 
Visita de Uliratumba, cuento, Editorial Alfaguara Infantil, Madrid, 2006; La cabeza de mi padre, novela corta en trece módulos, novela corta, Editorial Pre-Textos, Valencia, 2002; El cocodrilo llorón, cuento, Editorial Santillana, 2002; Los tres náufragos, cuento, Editorial Santillana, 2002; La sirenita sin vor, novela juvenil, Editorial Anaya, Madrid, 2000; Naufragio, novela, Editorial E.D.H.A.S.A., Barcelona, 1998; Editorial Plaza Mayor, Río Piedras, 1999; Segundo premio del Instituto de Literatura Puertorriqueña, 1999; La lámpara de vitrales, cuento, Editorial Santillana, 1996; Verano, novela, Grupo Editorial Norma S.A., Santafé de Bogotá, 1993; Grupo Editorial Mondadori-Grijalbo, Barcelona, 1995; Premio del Instituto de Literatura Puertorriqueña, 1994; Amor portatill, novela, Editorial Alfaguara, Madrid, 1989; Editorial Sudamericana, Buenos Aires, 1991; Editorial Diana, México, 1991; Grupo Editorial Grijalbo-Mondadori, Barcelona, 1996; Finalista del Premio Casa de las Améticas, 1989; Finalista del Premio Rómulo Gallegos, 1991; La estructura dialéctica de "El otoño del patriarca", critica literaria, Editorial de la Universidad de Puerto Rico, Río Piedras, 1988; El tramo ancla, antología de ensayos (ocho ensayos de Kalman Barsy), Editorial de la Universidad de Puerto Rico, Río Piedras, 1988; Melancólico belado de vainilla, relatos, Editorial Antillana, Río Piedras, 1987; Del nacimiento de la isla de Borikén y otros mararillosos sucesos, cuentos, Ediciones Huracán, Rio Piedras, 1982; Ediciones Casa de las Américas, La Habana, 1986; Premio de la Casa de las Américas, 1982. Libros publicados en húngaro: Apám arvonásai (La cabeza de mi padre), novela corta, Editorial Orpheusz, Budapest, 2000.

Publicaciones en Lateral: Renista de Cultura. Verga de caballo, Lateral:- Revista de Cultura, núm. 95, 2002, 12; ¿Qué es un nombre después de todo?, Lateral: Revista de Cultura, núm. 89, 2002, 34; El tesoro Benedek, Lateral: Revista de Cultura, núm. 72, 2000, 9; Triste domingo, Lateral: Revista de Cultura, núm. 65, 2000, 14; La rvelación, Lateral: Revista de Cultura, núm. 49, 1999; El jardin, Lateral: Revista de Cultura, núm. 31-32, 1997; Disney World. Viaje a otra dimensión, Lateral: Revista de Cultura, núm. 37, 1998.

Publicaciones en revistas húngaras: A Benedek kincs, Lettre, núm. 37, verano de 2000; Úton Disneylandbe, PoLiSz, núm. 9. 